\title{
Assessment of sandy soil water permeability methods
}

\author{
Andrey Nikitin ${ }^{1, *}$ \\ ${ }^{1}$ Northern Federal University named after M.V. Lomonosov (NArFU), Severnaya Dvina Emb., 17, \\ Arkhangelsk, 163002, Russia
}

\begin{abstract}
Qualitative assessment of soil permeability is important for designing drainage systems and waterworks. According to the research results, soil permeability factor depends on sample preparation, test method and conditions.

The article summarizes the results of analyzing the factors that influence the permeability of sandy soils: filtration conditions (steady-state and nonsteady-state), sample area, compaction method, and sample height.

Water permeability of sand in field conditions was determined by filling a pit with water at a constant head and a stable flow rate. The soil surveyed was medium-grained sand of medium density located above the groundwater table.

Permeability testing in laboratory conditions was carried out using filtration tubes with the area of 20 and $85 \mathrm{~cm}^{2}$. The height of the soil samples was 50 and $100 \mathrm{~mm}$. The laboratory test results showed that the sand permeability factor greatly depends on the compaction method: layerby-layer compaction, vibration compaction. Different permeability factor values for the surveyed soil were caused by non-uniform vertical compaction of the sample. With the standard test method, the deviation of laboratory test results from the field test results reached 16 to $28 \%$.

When using sand compaction by tamping, the results closest to the actual permeability can be achieved by selecting an optimum weight drop height and reducing the sample height. Meanwhile, filtration conditions and sample area have a negligible effect on sand permeability. The article demonstrates that selecting an optimal compaction method ensures the error of permeability factor determination in laboratory conditions within $5 \%$.
\end{abstract}

\section{Introduction}

In many cases, building design requires exact calculation of soil permeability factor. It can be determined by laboratory or field methods. In field conditions, the most commonly used methods include water filling into a pit and water pumping. Laboratory methods of permeability determination take less lime and effort. Preliminary assessment of water

\footnotetext{
*Corresponding author: nikitinavsafu@yandex.ru
} 
permeability also uses calculation methods that take into account the grain-size composition and physical properties of soil. However, water permeability calculation methods are less accurate [4].

The results of numerous experiments have shown that the soil permeability factor depends on the test method, the design features of the instruments, the sample preparation methods, the head gradient, etc. [2-3,5]. Besides, water permeability is influenced by the chemical composition and temperature of the infiltrating fluid [6, 7, 8, and 9]. Water in sludge dumps may contain a significant amount of chemicals, which considerably increases its filtration rate in soil.

The aim of the study was to assess the reliability of laboratory methods for determining water permeability of sandy soils.

\section{Field experiments}

The method of water filling into a pit was employed to determine the permeability factor in field conditions. The apparatus (infiltrometer) consisted of two concentric rings (Figure 1). The inner ring had the diameter of $0.37 \mathrm{~m}$, and the outer ring $-0.52 \mathrm{~m}$. The infiltrometer was placed into an open pit $0.5 \mathrm{~m}$ deep and submerged into the base by $2 \mathrm{~cm}$. A $2 \mathrm{~cm}$ thick crushed stone layer was made on the pit bottom. The distance from the pit bottom elevation to the groundwater table was $3.2 \mathrm{~m}$. During the experiment, water was supplied continuously into the inner and the outer ring of the infiltrometer up to a certain level. The water level in the rings was maintained $10 \mathrm{~cm}$ above the ground level. The temperature of the infiltrating water during the experiment was $4{ }^{\circ} \mathrm{C}$.

Samples from open pits were taken to determine the grain-size composition, density, and permeability factor in laboratory conditions. Table 1 gives the grain-size composition of the soil under investigation. The soil density is $1.71 \mathrm{~g} / \mathrm{cm}^{3}$, moisture content $-6.2 \%$, porosity coefficient -0.649 . The soil is represented by medium-grained sand of medium density. The permeability factor reduced to the filtration at $10{ }^{\circ} \mathrm{C}$ was determined by formula:

$$
k_{10}=\frac{Q}{A t T},
$$

where $Q$ is the volume of filtered water;

$A$ is the area of the infiltrometer's inner ring;

$T$ is the correction factor to reduce the water permeability factor to $10^{\circ} \mathrm{C}, T=0.7+.03 T_{0}$.

Table 1. Grain-size composition of sandy soil.

\begin{tabular}{|c|c|c|c|c|c|}
\hline \multicolumn{7}{|c|}{ Content of particles, \%, of size, mm } \\
\hline $5-2$ & $2-1$ & $1-0.5$ & $0.5-0.25$ & $0.25-0.10$ & $<0.1$ \\
\hline 0.0 & 0.03 & 0.62 & 50.4 & 48.8 & 0.15 \\
\hline
\end{tabular}

Table 2 gives the results of sand permeability factor determination in field conditions.

Table 2. Sandy soil permeability by field test results.

\begin{tabular}{|c|c|c|c|c|}
\hline $\begin{array}{c}\text { Water } \\
\text { volume, } \\
\text { liter }\end{array}$ & Ring area, $\mathrm{cm}^{2}$ & Filtration time, $\mathrm{s}$ & $\begin{array}{c}\text { Permeability } \\
\text { factor, m/day }\end{array}$ & $\begin{array}{c}\text { Permeability } \\
\text { factor } k_{10}, \mathrm{~m} / \text { day }\end{array}$ \\
\hline 15 & 1075 & 688 to 713 & 16.91 to 17.52 & 20.92 \\
\hline
\end{tabular}




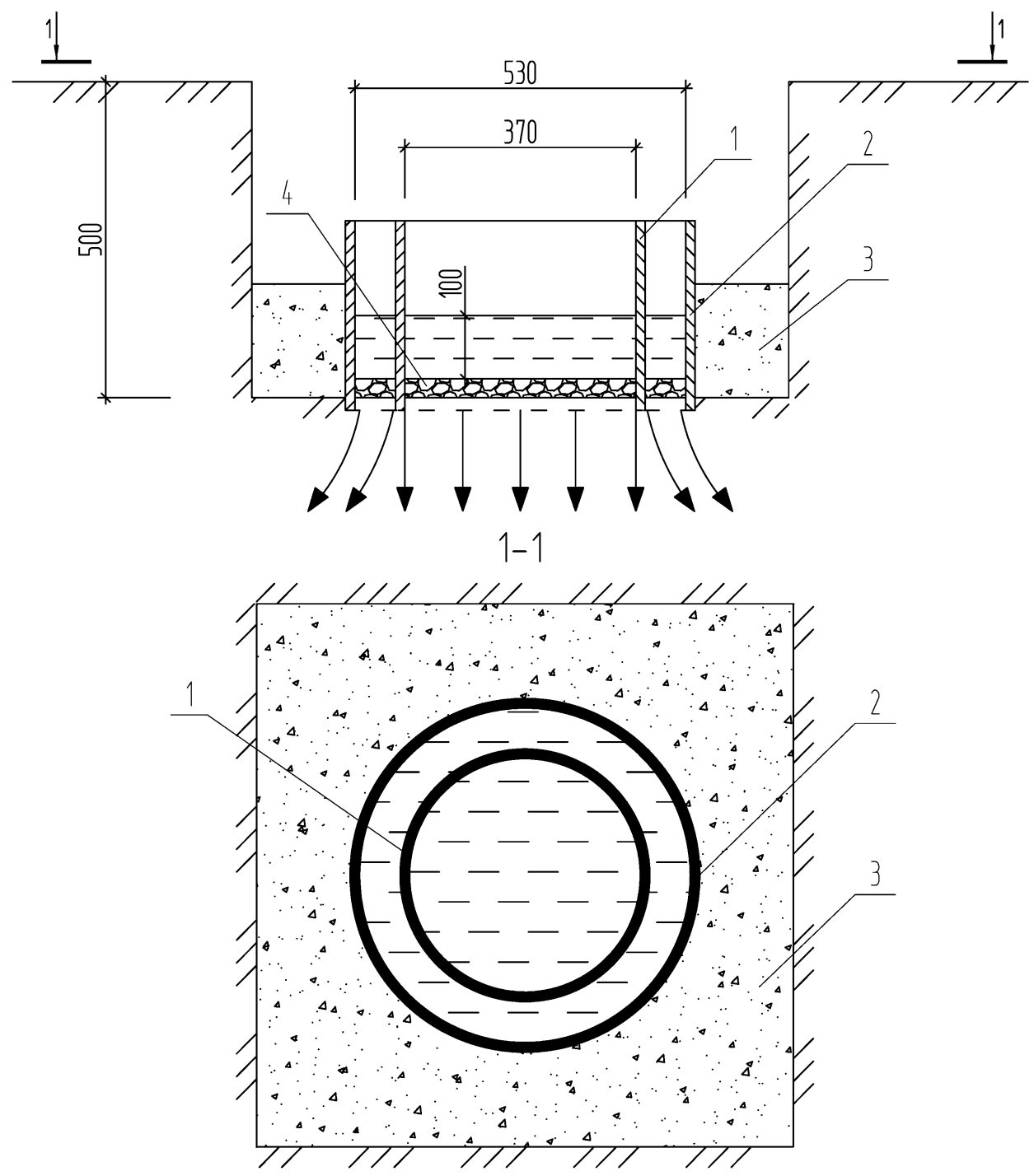

1 - infiltrometer's inner ring, 2 - infiltrometer's outer ring, 3 - compacted soil, 4 - crushed stone

Fig. 1. Field apparatus to determine sand permeability.

The permeability factor value is characteristic of medium-grained sand and ranges from 20 to $50 \mathrm{~m} /$ day [1].

\section{Laboratory experiments}

Laboratory methods of permeability testing are among the simplest and most frequently used. Sand testing in the laboratory was carried out with filtration tubes at steady-state and non-steady-state filtration conditions (Figure 2). The impact of sample area, compaction method, sample height, and filtration conditions on the permeability factor was studied. 


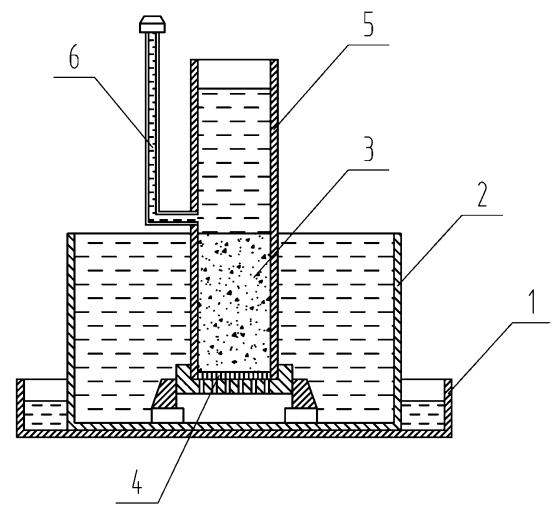

$a$

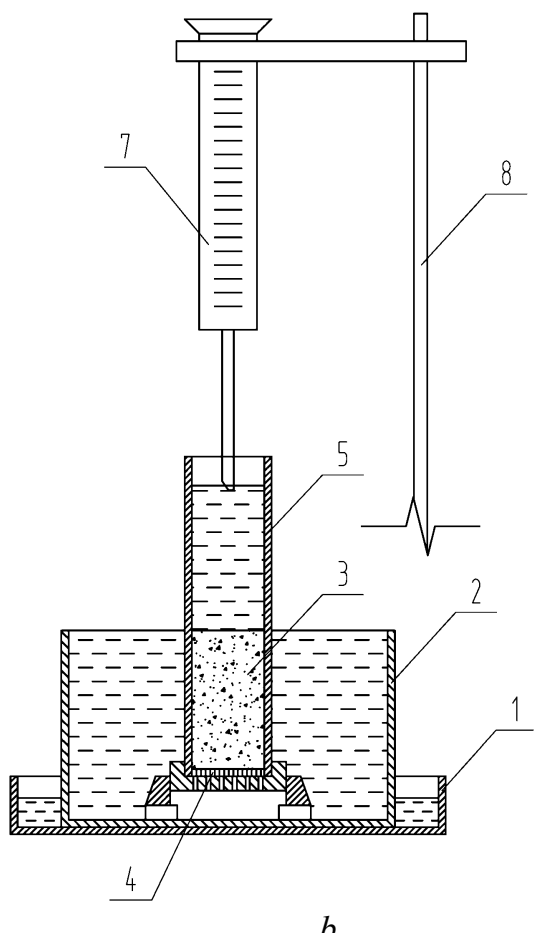

b

$a$ - steady-state filtration condition, $b$ - non-steady-state filtration condition 1 - pan, 2 - glass, 3 - soil sample, 4 - porous filter, 5 - filtration tube, 6 - piezometer, 7 - glass measuring cylinder, 8 - holder

Fig. 2. Testing schemes for sandy soil.

Filtration tubes with the area on 20 and $85 \mathrm{~cm}^{2}$ were used to determine permeability. The sample height in filtration tubes was $100 \mathrm{~mm}$. Brass mesh covered with geotextile was used as the filter at the tube bottom.

Steady-state filtration testing was carried out at head gradients $0.2,0.4,0.6,0.8$, and 1.0. Under non-steady-state conditions, the time of water level decrease in piezometers by 1,2 , 3,4 , and $5 \mathrm{~cm}$ was recorded. The tubes were filled with $2 \mathrm{~cm}$ thick soil layers, each layer was compacted by tamping. The number of tamping blows was identified in two stages. At the first stage, the total number of blows for sample compaction was established. At the second stage of layer-by-layer compaction, the blows were equally distributed among the layers.

When using a $20 \mathrm{~cm}^{2}$ filtration tube, a standard tamper with $0.5 \mathrm{~kg}$ weight was dropped from the height of $30 \mathrm{~cm}$. For the $85 \mathrm{~cm}^{2}$ tube, the weight was $2 \mathrm{~kg}$ with the same drop height. The sand samples were compacted to the density corresponding to the soil density in field conditions. Table 3 gives the sand permeability factor values at the actual water temperature and at $10^{\circ} \mathrm{C}$.

The permeability factor under steady-state conditions was determined by formula:

$$
k=\frac{v}{I}
$$

where $v$ is the filtration rate;

$I$ is the head gradient. 
Under non-steady-state conditions, the permeability factor was calculated by formula:

$$
k=\frac{\ln \left(\frac{H_{0}}{H_{0}-S}\right)}{\frac{F_{k} t}{F_{n} l_{k}}},
$$

where $H_{0}$ is the initial water level in the piezometer;

$S$ is the reduction of water level in the piezometer;

$t$ is the time of water level decrease;

$F_{k}$ is the soil sample cross section area;

$F_{n}$ is the filtration tube area;

$l_{k}$ is the soil sample height.

Table 3. Sandy soil permeability at standard test parameters.

\begin{tabular}{|c|c|c|c|c|}
\hline $\begin{array}{c}\text { Filtration } \\
\text { conditions }\end{array}$ & Tube area, $\mathrm{cm}^{2}$ & $\begin{array}{c}\text { Water } \\
\text { temperature, }{ }^{\circ} \mathrm{C}\end{array}$ & $\begin{array}{c}\text { Permeability } \\
\text { factor, } k, \mathrm{~m} / \text { day }\end{array}$ & $\begin{array}{c}\text { Permeability } \\
\text { factor } k_{10}, \mathrm{~m} / \text { day }\end{array}$ \\
\hline steady-state & 20 & 23 & 24,50 & 17,61 \\
\hline non-steady-state & 20 & 23 & 20,54 & 15,10 \\
\hline steady-state & 85 & 21 & 22,46 & 17,27 \\
\hline
\end{tabular}

Table 3 shows that the filtration tube area has no impact on sand permeability. Under non-steady-state filtration conditions, the permeability factor is $17 \%$ lower than that at steady-state conditions. The deviation of the permeability factor value from field test data reaches 16 to $28 \%$. The difference in the permeability factor values is due to overcompaction of the soil sample bottom layers.

When you determine the permeability factor in laboratory conditions, it is necessary to ensure uniform vertical compaction of the sample. To improve the accuracy of laboratory tests, experiments were conducted with the sample height of $50 \mathrm{~mm}$, compaction by tamping, and weight drop height reduced to $15 \mathrm{~cm}$. Besides, the impact of vibration compaction to sand permeability was studied. Vibration compaction of samples was carried out on a platform with the adjustable vibration frequency. The sample compaction time depended on how quickly the required density was achieved. The test results are given in Figure 3 and Table 4.

Table 4. Sandy soil permeability at optimized test parameters.

\begin{tabular}{|c|c|c|c|c|c|}
\hline $\begin{array}{c}\text { Compaction } \\
\text { method }\end{array}$ & $\begin{array}{c}\text { Sample } \\
\text { height, } \\
\mathrm{mm}\end{array}$ & $\begin{array}{c}\text { Tube } \\
\text { area, } \\
\mathrm{cm}^{2}\end{array}$ & $\begin{array}{c}\text { Water } \\
\text { temperature, }{ }^{\circ} \mathrm{C}\end{array}$ & $\begin{array}{c}\text { Permeability } \\
\text { factor, } k, \mathrm{~m} / \text { day }\end{array}$ & $\begin{array}{c}\text { Permeability } \\
\text { factor } k_{10}, \\
\mathrm{~m} / \mathrm{day}\end{array}$ \\
\hline tamping & 50 & 20 & 23 & 26.68 & 19.19 \\
\hline $\begin{array}{c}\text { vibro } \\
\text { compaction }\end{array}$ & 100 & 20 & 20 & 20.03 & 15.41 \\
\hline tamping & 50 & 85 & 21 & 25.23 & 19.40 \\
\hline
\end{tabular}

Vibration compaction cannot ensure uniform compaction of sandy soil samples and improve the accuracy of laboratory filtration tests. Tamping with a reduced sample height and a tamper weight drop height reduced to $15 \mathrm{~cm}$ has proven to be the most effective method ensuring minimum deviations from the field permeability test results. The high accuracy of permeability factor determination at the optimized test parameters is due to the uniform vertical compaction of sand. 


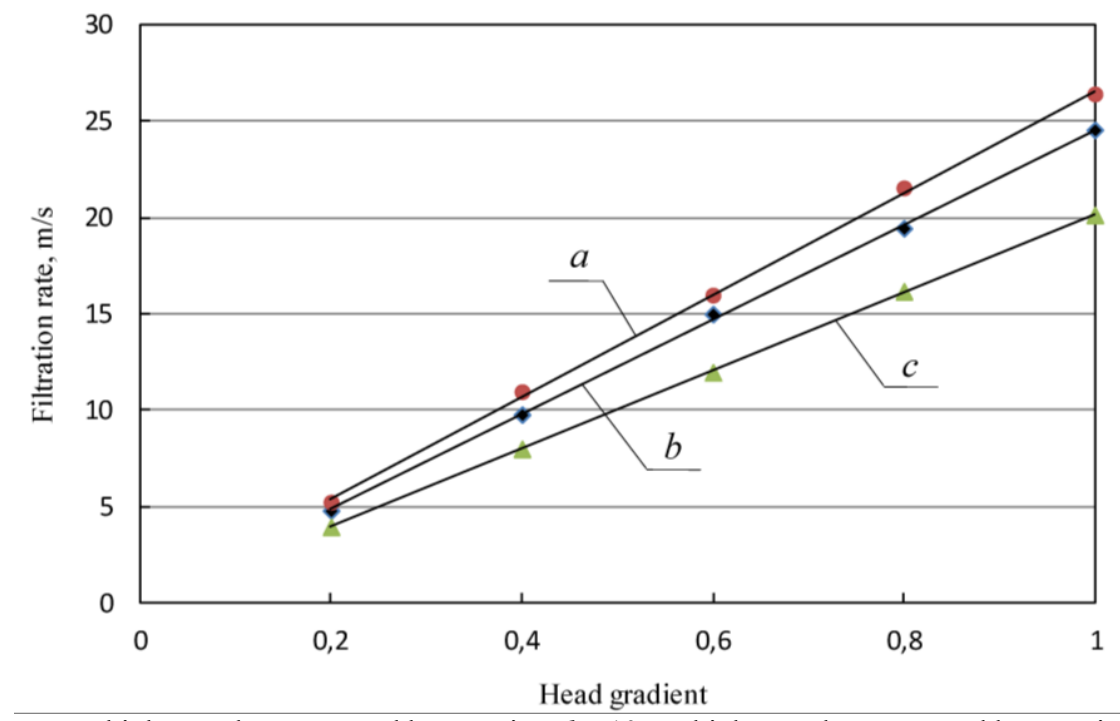

$a-5 \mathrm{~cm}$ high sample compacted by tamping, $b-10 \mathrm{~cm}$ high sample compacted by tamping, $c-10 \mathrm{~cm}$ high sample compacted by vibration.

Fig. 3. Filtration rate plotted against hydraulic with a tube area of $20 \mathrm{~cm}^{2}$.

\section{Conclusion}

1. The method of sample preparation for laboratory testing of sand permeability has a considerable impact on the permeability factor value.

2. The deviation of laboratory-based sandy soil permeability test results from field test data reaches 16 to $28 \%$.

3. Optimized sand filtration test methods ensure a considerable improvement of laboratorybased permeability test results.

\section{References}

1. Pile foundation design guidelines (1980)

2. V.E. Levkevich, D.E. Mikanovich, V.A. Tsedic, Probl. Saf. Emer. Situat., 1(3), 63-65 (2014)

3. A.E. Kasianov, Environ. Eng., 2 , 26-28 (2012)

4. V.Ia. Zharnitskii, Hydr. Eng., 4, 37-42 (2010)

5. G. Velkovsky, D. Karastoyanov, Problems of Engineering Cybernetics and Robotics, 61, 21-28 (2009)

6. G.I. Kasperov, V.E. Levkevich, S.M. Pastukhov, M.S. Kuvshinov, A.V. Buzuk, D.S. Mikanovic, V.V. Kobyak, Bull. Officer Eng. Inst. Repub. Belarus' Emer., 2, 7378 (2015)

7. V.N. Zhilenkov, J. Vedeneev VNIIG, 235, 39-46 (1999)

8. V.M. Goldberg, N.P. Skvortsov, Earth's crust research challenges, 133-139 (1990)

9. D.L. Goodrich, War. Well J., 6, 27 (1989) 